\title{
Of Vessels, Conduits and Instruments: Reflections from the Bodies as Media Working Group
}

Nelesi Rodriguez

Eugenia Manwelyan 


\section{Abstract}

In the fall of 2016, a group of artists and educators met regularly over the course of three months to explore the many ways in which the human body mediates experience and knowledge. In their time working together, the Bodies as Media Working Group (BaM) explored the ways in which the (human) body comes to know, understand, and communicate ancestry, memory, ecology, emotionality, creativity, and even death. This working group was created as part of the School of Apocalypse (SoA), a NYC-based community of learning that examines connections between creative practice and survival. The $\mathrm{BaM}$ working group encapsulated its learning process by designing and producing a resource in the form of a deck of cards containing instructions and prompts meant to be activated as a ritual that aims to "turn on" people's body awareness and to prepare their bodies to learn. In designing a pedagogical tool for the body, $\mathrm{BaM}$ aims to reconstitute the individual and social body contained most commonly in the classroom as open, trusting, and alert. The tool thereby redesigns the space within which learning takes place without making any physical alterations to it, but rather by reconfiguring the group's relationship to it and within it.

\section{Keywords:}

body, medium, tool, learning, ritual, pedagogy, classroom 


\section{Resumen}

Durante el otoño de 2016, un grupo de artistas y educadores se reunió regularmente a lo largo de tres meses para explorar las numerosas maneras en las que el cuerpo humano puede mediar experiencia y conocimiento. Durante el período de trabajo conjunto, el grupo "Cuerpos como medios" (Bodies as Media-BaM) exploró la forma en la que el cuerpo nos ayuda a conocer, absorber y comunicar conocimiento ancestral, memoria, ecología, emocionalidad, creatividad e incluso la muerte. Este grupo de trabajo se creó en el contexto de la Escuela del Apocalipsis (School of Apocalypse-SoA), una iniciativa con base en NYC que analiza las relaciones entre la supervivencia y las prácticas creativas. E1 BaM encapsuló las lecciones aprendidas durante su trabajo en conjunto, diseñando y produciendo un recurso en forma de un mazo de cartas con una serie de instrucciones para ejecutar un ritual que busca activar los cuerpos de los individuos involucrados en cualquier experiencia de aprendizaje. Al diseñar una herramienta pedagógica para el cuerpo, el BaM intenta reconstituirlo en su naturaleza individual y social y transformar el cuerpo comúnmente reprimido en el aula en uno abierto, cómodo y alerta. Por lo tanto, la herramienta rediseña el espacio en el que tiene lugar el aprendizaje, sin necesidad de alteraciones físicas, sino modificando la relación de los cuerpos con respecto a sí mismos, entre ellos, y con su entorno.

\section{Palabras clave:}

cuerpo, medio, herramienta, aprendizaje, ritual, pedagogía, aula 


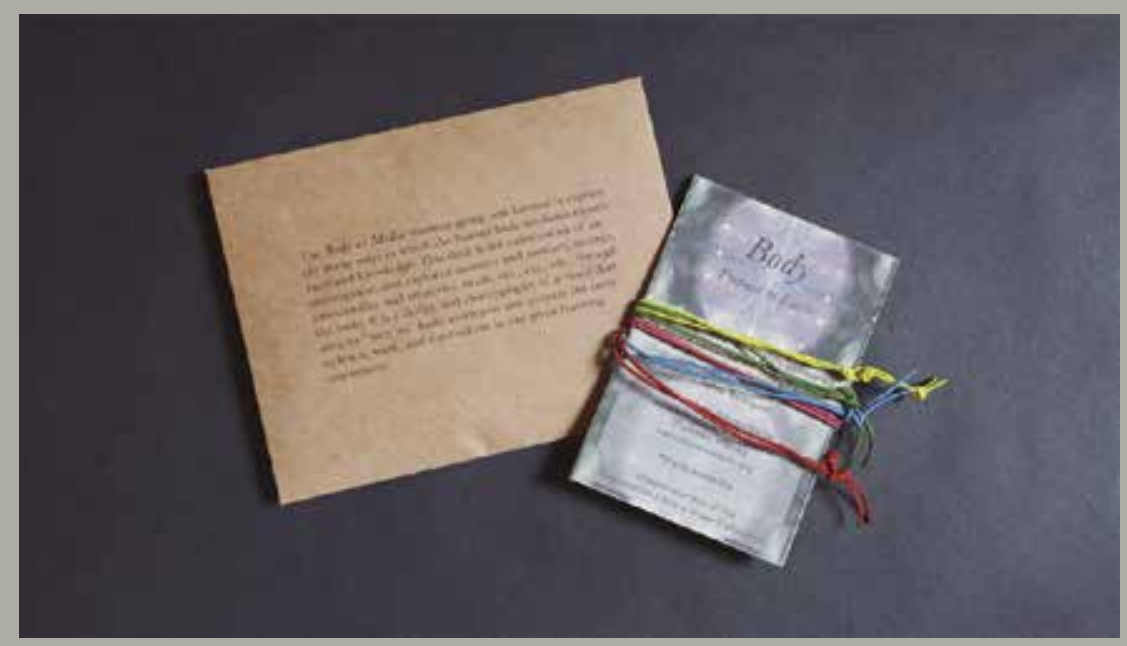

A deck of cards, wristbands, and an envelope - elements of the tool developed by BaM

\section{Take a deep breath and be perfectly still...}

Hesitant, some people in the room comply. Others, trusting, even close their eyes, as if this line were part of a score they already knew by heart. Hold your breath. Notice the body part that feels most restless. Here and there, eyes start scanning the room for clues and reassurance - they find them. Notice the thoughts and feelings that come up through this stillness. By now, everyone in the room seems to be in sync through this moment for introspection. People are attentive, waiting to hear what the leading voice will say next. When you just can't hold your breath any longer, exhale and release that body part - give it all the movement it calls for. That last instruction, given with perfect timing, is much appreciated, unleashing yawns, stretches, swings, and sighs enacted by the bodies in the room. Bodies that have arrived to a sterile classroom now find themselves having subtly subverted its most familiar "come in - sit down - stop talking - pay attention to the teacher" pathway. This simple act that is at once novel and embodied generates energy, alertness, and a sense that something new and unexpected can happen. Now, let the lesson begin. 


\section{Designing Embodied Pedagogies for Effective Learning}

In the fall of 2016, a group of artists and educators met regularly over the course of three months to explore the many ways in which the human body mediates experience and knowledge. In their time working together, the Bodies as Media Working Group (BaM) explored the ways in which the (human) body comes to know, understand, and communicate ancestry, memory, ecology, emotionality, creativity, death. This working group was created as part of the School of Apocalypse, a NYC-based community of learning that examines connections between creative practice and survival.

The School of Apocalypse has no fixed definition of apocalypse or survival, but engages with the fundamental questions that the themes provoke. Its rotating faculty invites a range of thinkers, artists and practitioners to present programming on topics that fit this realm of exploration. Subjects of study are theoretical as well as hands on, and emphasize the integration of observational and material practices found in mystical traditions, creative modalities and scientific field work. BaM emerged as a working group within the School of Apocalypse with these foundational questions: what are the qualities and consequences of body erasure in neoliberal society, and what are the ways in which the body is a powerful medium? BaM embarked on an experiential inquiry to investigate how the body survives and persists within a culture that is, in many ways, indifferent to its wisdom, fearful of its ephemerality, and disdainful of its leaks and needs.

The BaM working group encapsulated its learning process by designing and producing a resource for learning communities. In the form of a deck of cards containing instructions and prompts, the tool is meant to be activated as a ritual that aims to "turn on" people's body awareness and prepare their bodies to learn. A pedagogical tool for the body, the ritual proposed by $\mathrm{BaM}$ aims to reconstitute the individual and social body contained most commonly in the classroom as open, trusting, and alert. The tool thereby redesigns the space within which learning takes place without making any physical alterations to it, but rather by reconfiguring the group's relationship to it and within it. It is this open space that emerges within, between, and surrounding the present bodies that creates a fertile learning environment. The prompts on the cards the little games - act as invitations to arrive, to situate oneself through situating one's body, to connect with the intention to learn. 


\section{On the Epistemologies of the Body as Media}

Contemporary society seems to be on a resolute quest to erase the human body: significant developments in virtual reality, social spaces that rely solely on digital interface, automation and drones, self-driving cars, wearable devices... they all represent efforts to make our world a bodiless one. Currently, many digitally mediated practices are shaping and being shaped by the contemporary paradigm of the productive self, a model in which individuals' identities are highly determined by their professions, people are expected to do what they love, and boundaries between life and work have collapsed. However, this take on the self that perceives the body as a tool (if not an obstacle) for productivity has not always been predominant. From the Hellenic practice of "taking care of the self" in preparation for political life - epimelesthai satou ${ }^{1}$ - to the quantified self, ${ }^{2}$ human beings have used their bodies as tools in many different ways. People's take on the body as a medium has shifted throughout time: bodies have been perceived as vessels to contain the self (i.e., religious subjectivities in which the body serves as a "host" for the soul for as long as a human being exists in the terrestrial plane); proxies to facilitate connection ( i.e., the very word "medium" in occultism is used to refer to a body that can be possessed by spirits and deities trying to establish communication with the physical world); canvases where society imprints its norms (i.e., discussions on essentialism and its opposite that emerged within feminist studies and have since expanded exponentially to consider gender, its troubles and its possible transformations); models to understand and shape the urban environment (i.e., Vitruvius and Le Corbusier exemplifying two distinct eras when architecture became tied to the human body and its proportions).

\author{
${ }^{1}$ In his seminar "Technologies \\ of the Self" (1982), Michel \\ Foucault looked at the simila- \\ rities and differences between \\ several technologies through \\ which humans have attempted \\ self-improvement across time, \\ including the Greek notion of \\ "taking care of the self". \\ 2 "Quantified self" is one of the \\ names people use to refer to \\ digital self-tracking, a practice \\ that consists of using digital \\ devices to monitor one or \\ more aspects of one's life in \\ order to assess and improve \\ oneself.
}

More recently, neoliberal societies characterized by atomized lives and decentralized mechanisms of control have reinforced perceptions of the body as a productive tool. This is a model that carries on without considering its human cost. As Jonathan Crary points out, "24/7 [an expression that embodies the nonstop pace characteristic of this period] is a time of indifference, against which the fragility of human life is increasingly inadequate". ${ }^{3}$ From social media moderators who spend hours in front of a computer looking at inappropriate content reported by users to freelancers who have to make themselves available any day at any time, the dynamics imposed by the neoliberal model have serious effects on people's physical, mental, and emotional health. Human bodies are subject to monitoring and regulation by different actors who seek to guarantee that these bodies keep up with the demands of neo-
${ }^{3} 2013$, p.70 

dangerous cues - teaching only to the mind and instrumentalizing the body to exhaustion.

Many of our most common places are designed, both socially and spatially, with the body as an incidental nuisance, rather than as the very site and nexus point where the goal of the space is achieved. Nowhere is this more obvious and insidious than in our modern-day classrooms. Forward facing desks designed to subvert desires to socialize and work together also serve to train the body in physical stillness. Compartmentalizing physical activity with proper learning activity reinforces the falsehood that thinking and learning happen in the "mind", while exercise and play happen in the body. In her book Teaching to Transgress: Education as the Practice of Freedom, the feminist scholar and radical educator Bell Hooks captures how deeply erased our bodies are in the classroom: "When I first became a teacher and needed to use the restroom in the middle of class, I had no clue as to what my elders did in such situations. What did one do with the body in the classroom?"

With this rationale as a starting point, the $\mathrm{BaM}$ working group wondered how the very notion of the body as a medium could be used to design a pedagogical and research tool to undermine the ideas of the "productive self." BaM wondered instead how the body could serve as a point of access to different ways of knowing, a repository of and connector between knowledge and experience, and as a means for transgression and connection between disciplines and beyond norms. Rather than exploring the latest horizons of somatic dematerialization, our research leverages the body's corporeal materiality in order to subvert the body erasure trends of the increasingly transhuman/posthuman contemporary cultures.

\section{The Ground and the Goal: Learning about the Body as a Medium for Learning}

The School of Apocalypse working groups are vessels for collaboration that gather individuals with different knowledge, experiences, and skills around a topic of common interest in order to discuss it, experiment with it, and create something together. Bodies as Media working group members met seven times over the course of three months. The first of those meetings was dedicated to setting up a structure and a plan for our collaboration. In the last two meetings, we workshopped and 
created a resource that is designed to be used by any group in order to activate and bring awareness to the body in preparation for the learning experience. During the four meetings in the middle, we explored four different instances of the body as a medium, one per session: the body as inheritor of ancestry and carrier of memory; the body as/and within an ecosystem; the body and (terrestrial) existence; and body and creativity. Through intellectual inquiry, experimentation, and play, working group members took turns leading experiences that unlocked body movements, poses, and processes long forgotten by many members of the group. Unlocking our bodies very often also meant unlocking our minds and our hearts.

We concluded that the body is a medium for a great many things, and that in order to connect with this tremendous wealth of information and knowledge one must understand and experience the body itself as a medium for learning. Contrary to how it is often treated in the classroom, the body is not a mobile unit that carries atop of it the great and powerful mind. All knowledge, everything we have ever known, we have learned in our bodies, and resides in our bodies to this day. To connect to all of this information, to understand the body as a medium for knowledge, we must open our whole selves to the learning moment. Thus, BaM created a sort of opener - a tool, designed to be used as a ritual in any learning environment in order to potentiate personal experience and community building.

\section{The Learning Tool as a Deck of Cards, a Ritual, a Choreography}

To activate the body as a medium for learning, $\mathrm{BaM}$ designed and produced a device that consisted of a deck of cards, each one with a score for a choreography (a collective action) that is meant to bring awareness to a specific way in which our bodies mediate experience and/or knowledge, and a set of wristbands in different colors, each one matching one card. This device provides the resources to perform a ritual to unlock movement, acknowledgement, and reflection in the bodies present in any learning setting. 


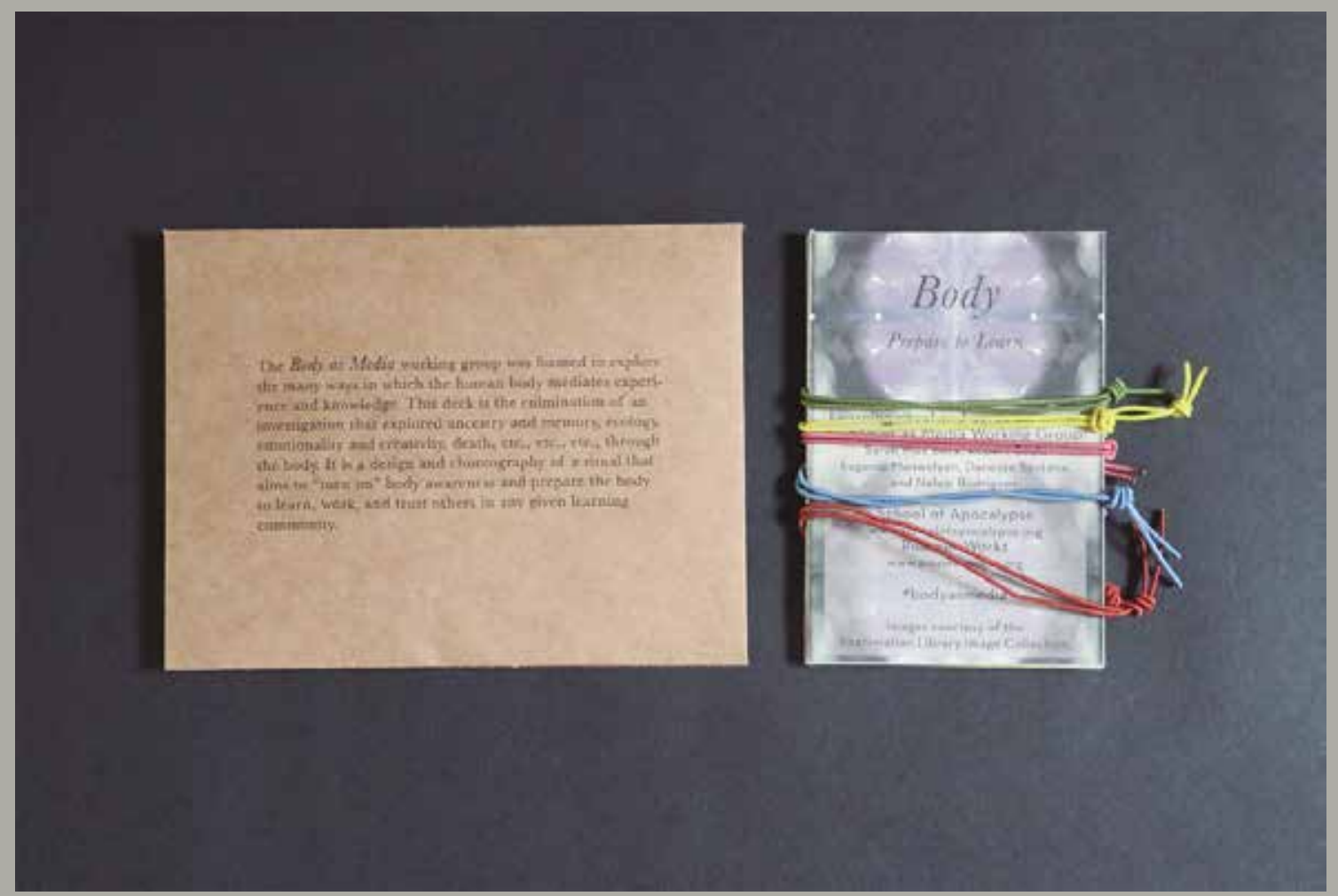

The tool designed by BaM: a deck of cards and a set of bracelets in an envelope.

The Body as Media working group was formed to explore the many ways in which the human body mediates experience and knowledge. This deck is the culmination of an investigation that explored ancestry and memory, ecology, emotionality and creativity, death, etc... etc... etc... through the body. It is a design and a choreography that aims to "turn on" body awareness and prepare the body to learn, work, and trust others in any given learning community. 


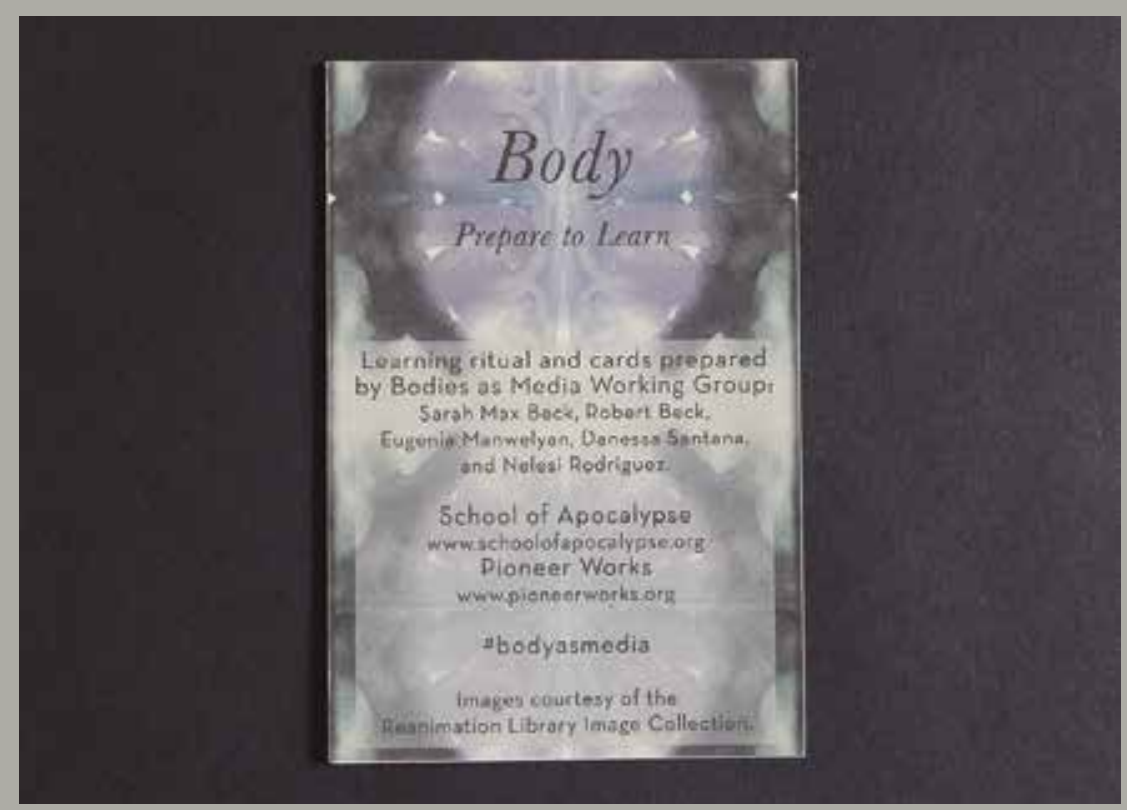

Introduction card, front.

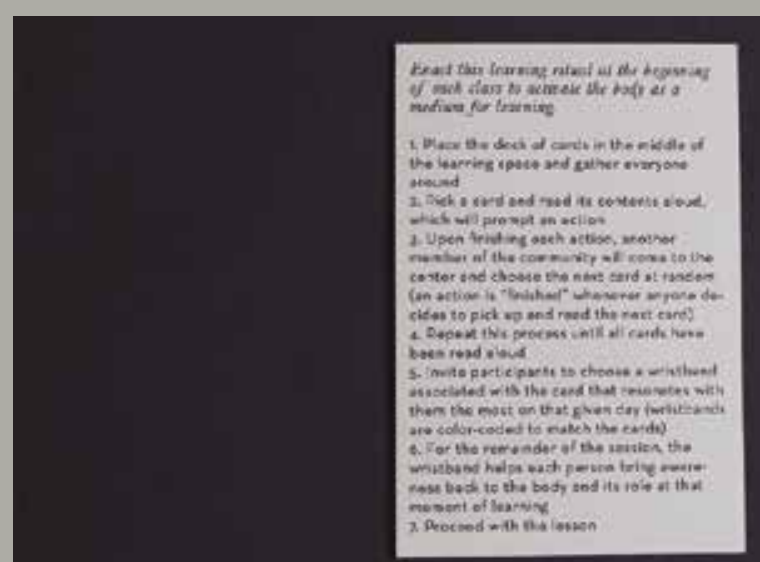

*Introduction card, back 
How to use the deck and wristbands:

For best results, enact this ritual at the beginning of each class to activate the body as a medium for learning.

1. Place the deck of cards in the middle of the learning space and gather everyone around.

2. Pick a card and read its contents aloud, which will prompt an action.

3. Upon finishing each action, another member of the community will come to the center and choose the next card at random. (An action is "finished" whenever anyone decides to pick up and read the next card.)

4. Repeat this process until all the cards have been read aloud.

5. Invite participants to choose a wristband associated with the card that resonates with them the most on that given day. (Wristbands are color-coded to match the cards.)

6. For the remainder of the session, the wristband helps each person to bring awareness back to the body and its role at that moment of learning.

7. Proceed with the lesson. 


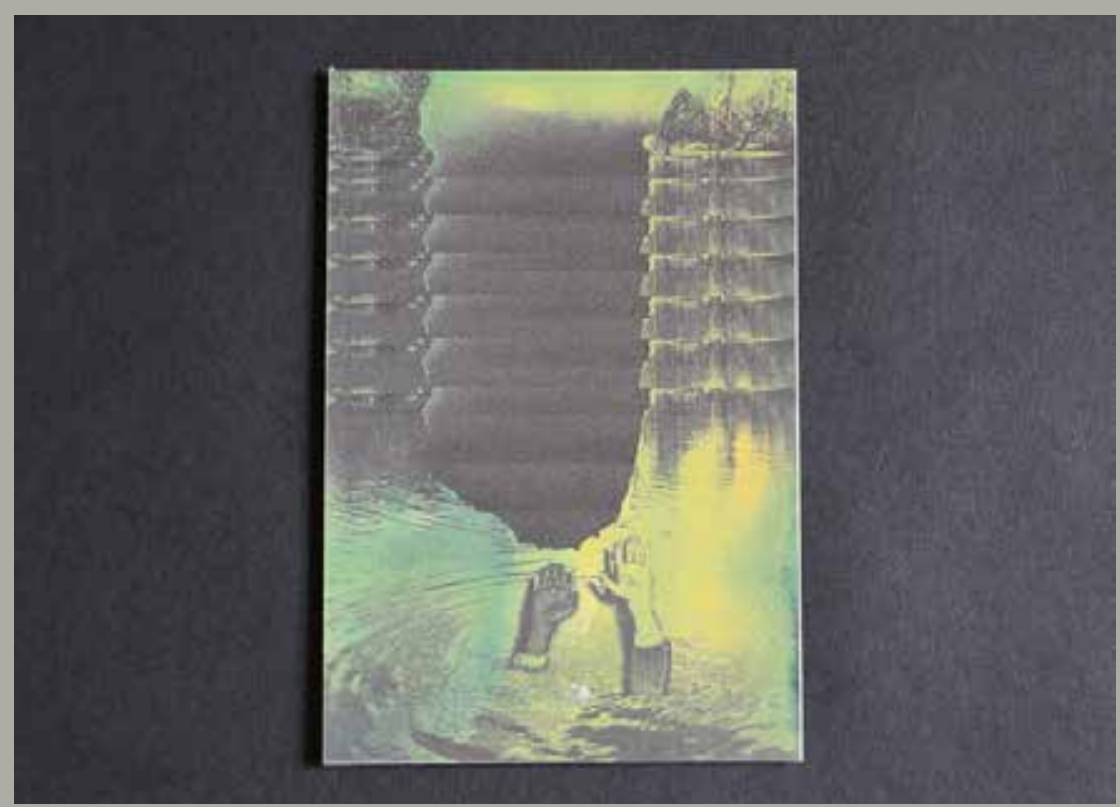

Emotional and Psychological Exposure card, front

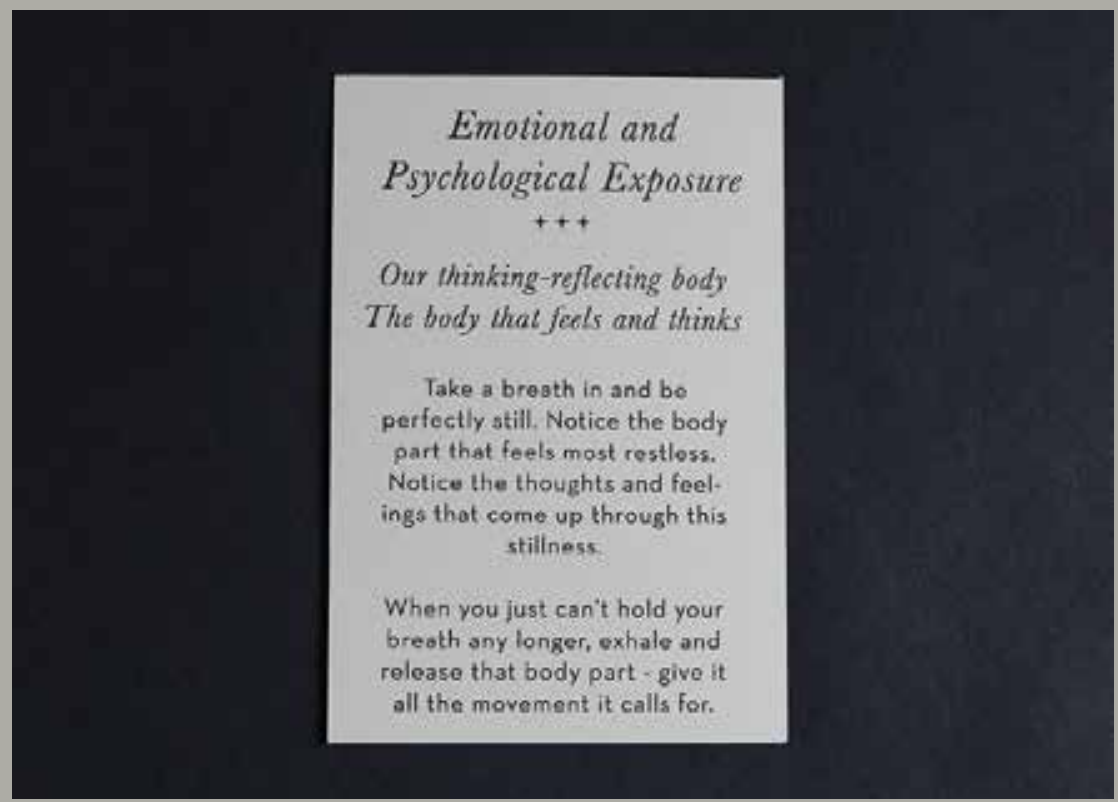

*Emotional and Psychological Exposure card, back 
Emotional and Psychological Exposure

Some emotions and states of mind squat in our bodies. As a result, our muscles tense up, we hunch, we forget to breathe - we somatize. Locating the signs of particular emotions and thoughts in the body and acting upon it, we can try to turn around that vectoral relationship (from psyche $\rightarrow$ body to body $\rightarrow$ psyche).

Psychotizing or emotizing as an antidote to somatizing.

Emotional and Psychological Exposure

Our thinking-reflecting body

The body that feels and thinks

Take a deep breath and be perfectly still. Notice the body part that feels most restless. Notice the thoughts and feelings that come up through this stillness. When you just can't hold your breath any longer, exhale and release that body part - give it all the movement it calls for. 


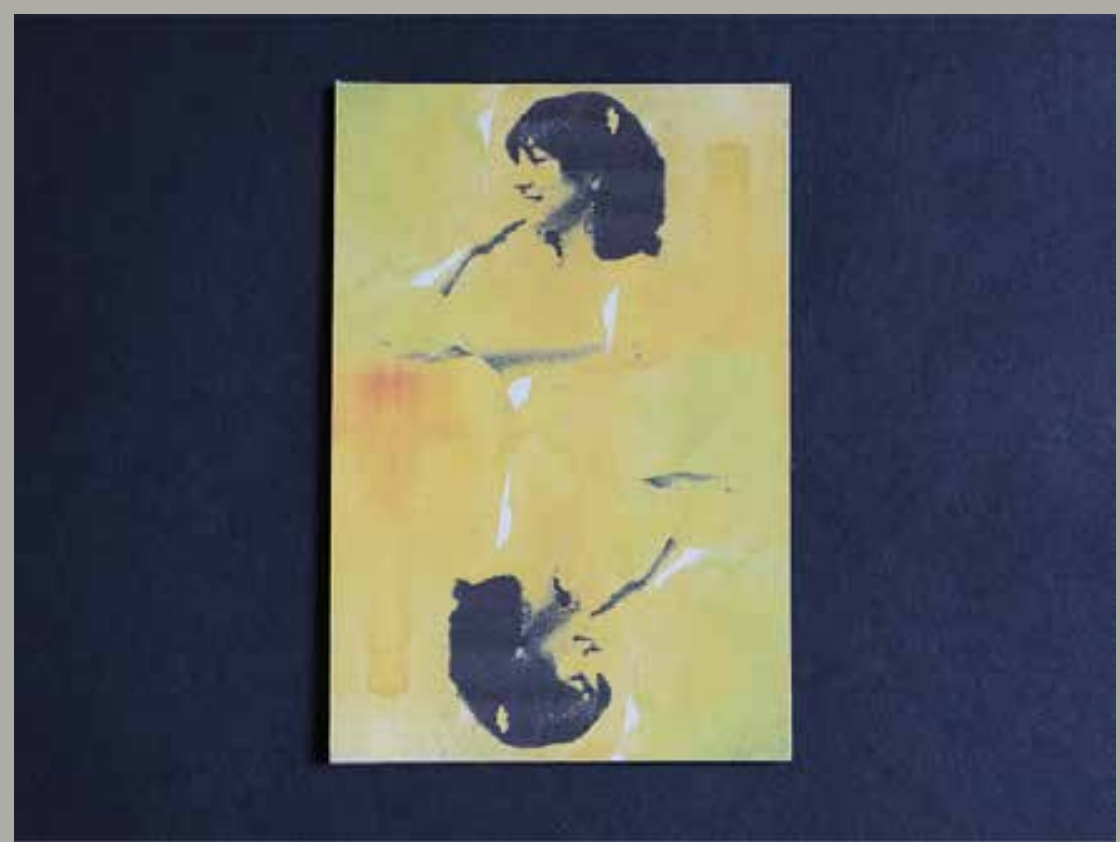

Heredity $\mid$ Ancestry $\mid$ Memory card, front

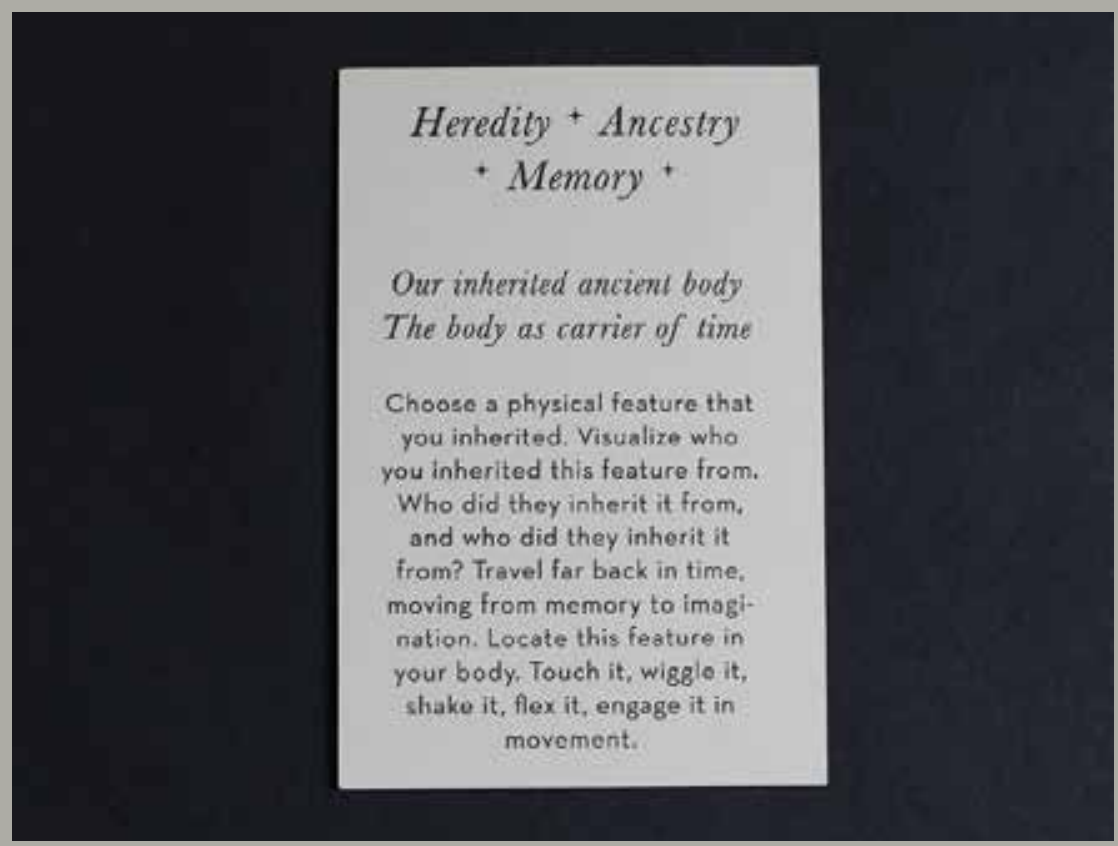

"Heredity|Ancestry|Memory card, back 
Heredity, Ancestry, and Memory

Inspired by recent research on embodied ancestral trauma, this card invites people to think of their bodies as repositories of knowledge and experience passed down by previous generations and at the same time as collectors of information and wisdom that will be imprinted on the ones to come. If our bodies can hold traumas from our ancestors, what other types of knowledge do our bodies inherit? And, more importantly, how can we access that knowledge and work with it? Our inherited bodily features can serve as an entry point to ancestral insight.

Heredity $\mid$ Ancestry $\mid$ Memory

Our inherited-ancient body

The body as a carrier of time

Choose a physical feature that you have inherited. Visualize who you inherited this feature from. Who did they inherit it from, and who did they inherit it from? Travel far back in time, moving from memory to imagination.

Locate this feature in your body. Touch it, wiggle it, shake it, flex it, engage it in movement. 


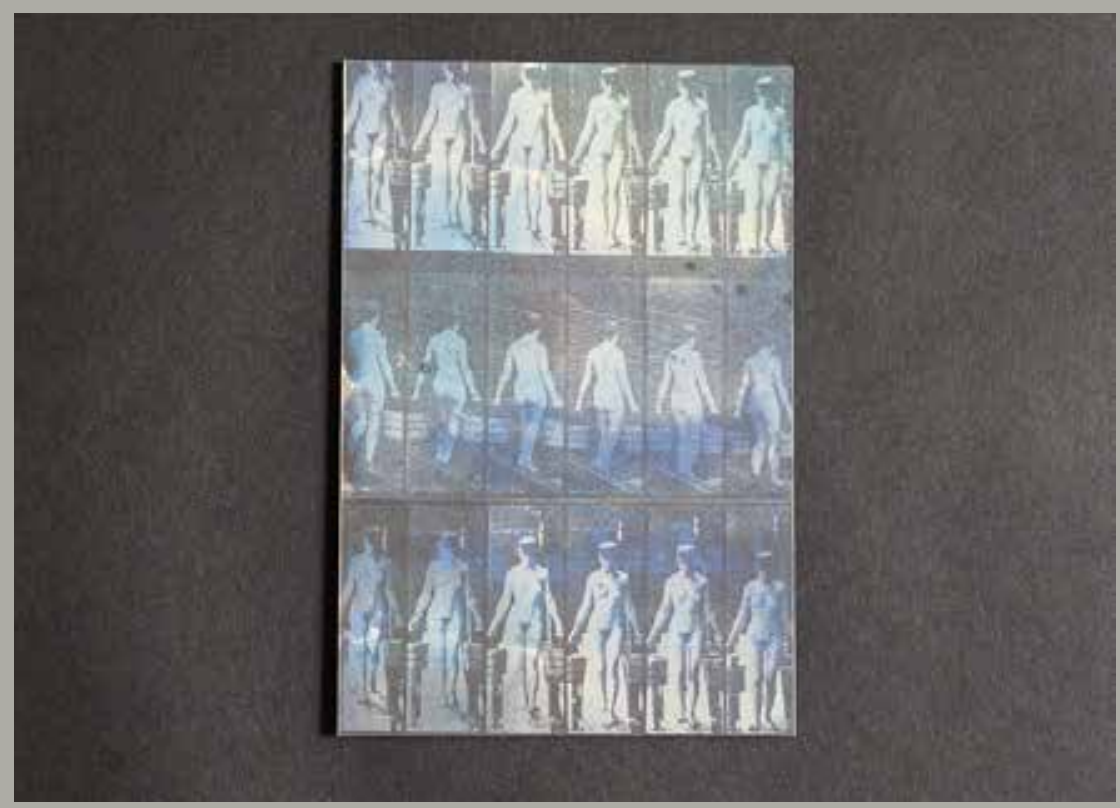

Environment $\mid$ Culture card, front

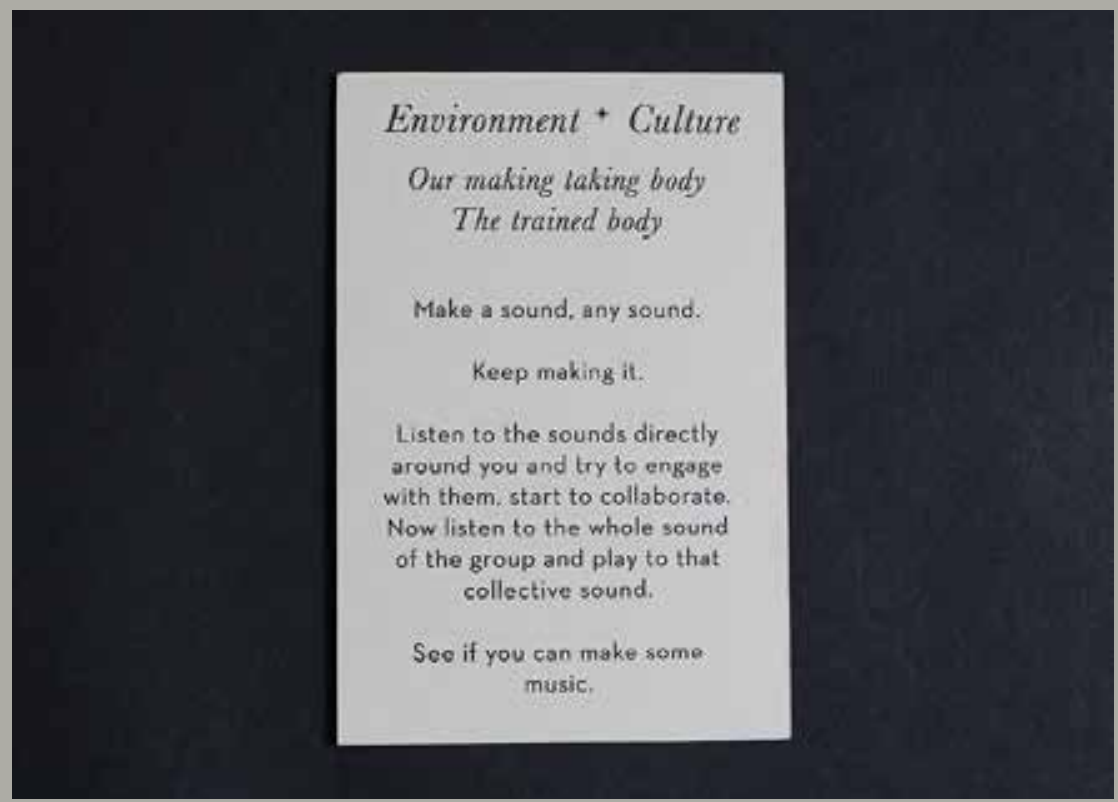

Environment|Culture card, back 


\section{Environment - Culture}

How does the body exist and negotiate its way through the economies of the living? The body is this ultimate producer - of things, of other bodies, of ideas - and through some series of exchanges and value propositions, the body makes its way through the world, via its cultural pathways. The body learns, in its most porous moments, it appropriates and makes its own that which was everyone's and no one's. At once a producer, consumer, steward, and inheritor of culture, the body works to understand, interpret, and impact the external world. The body is able, quite magically, to synthesize and make sense of the cacophony of sights and sounds around us, so as to harmonize with it and within it.

\section{Environment $\mid$ Culture}

Our making-taking body

\section{The trained body}

Make a sound, any sound. Keep making it. Listen to the sounds directly around you and try to engage with them, start to collaborate. Now listen to the whole sound of the group and play to that collective sound. See if you can make some music. 


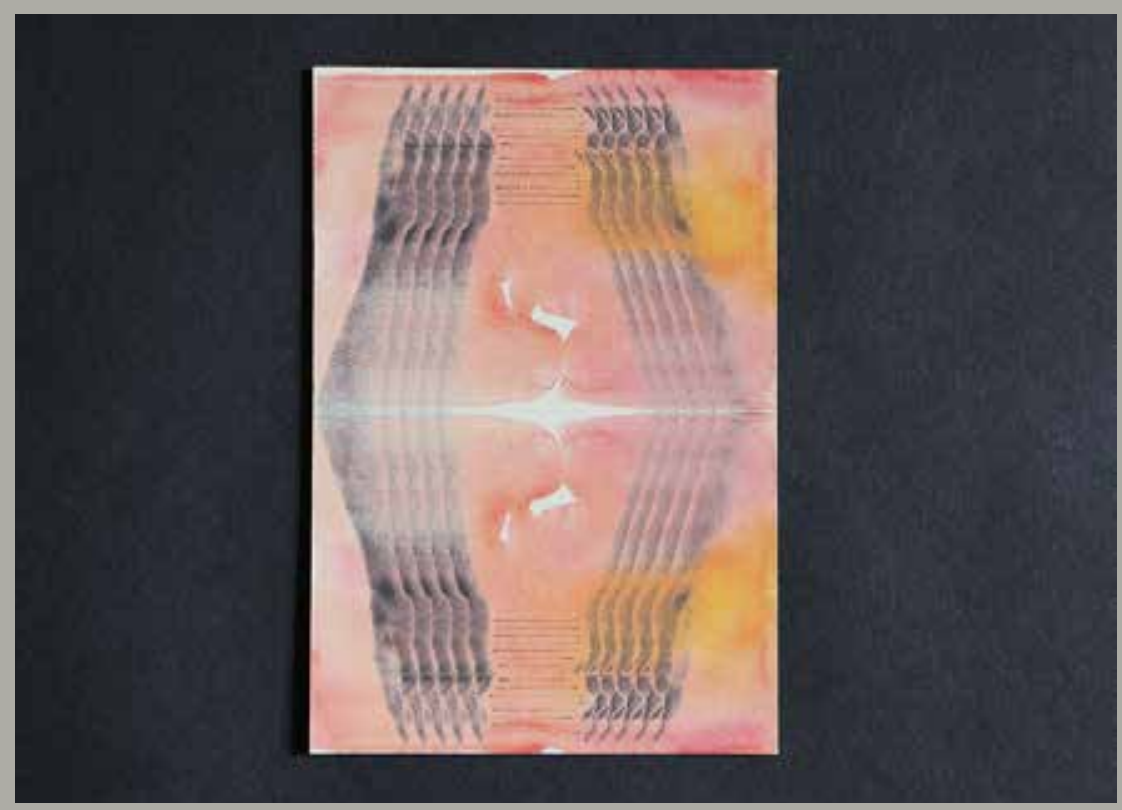

Nutrition|Transformations|Inputs and Outputs card, front

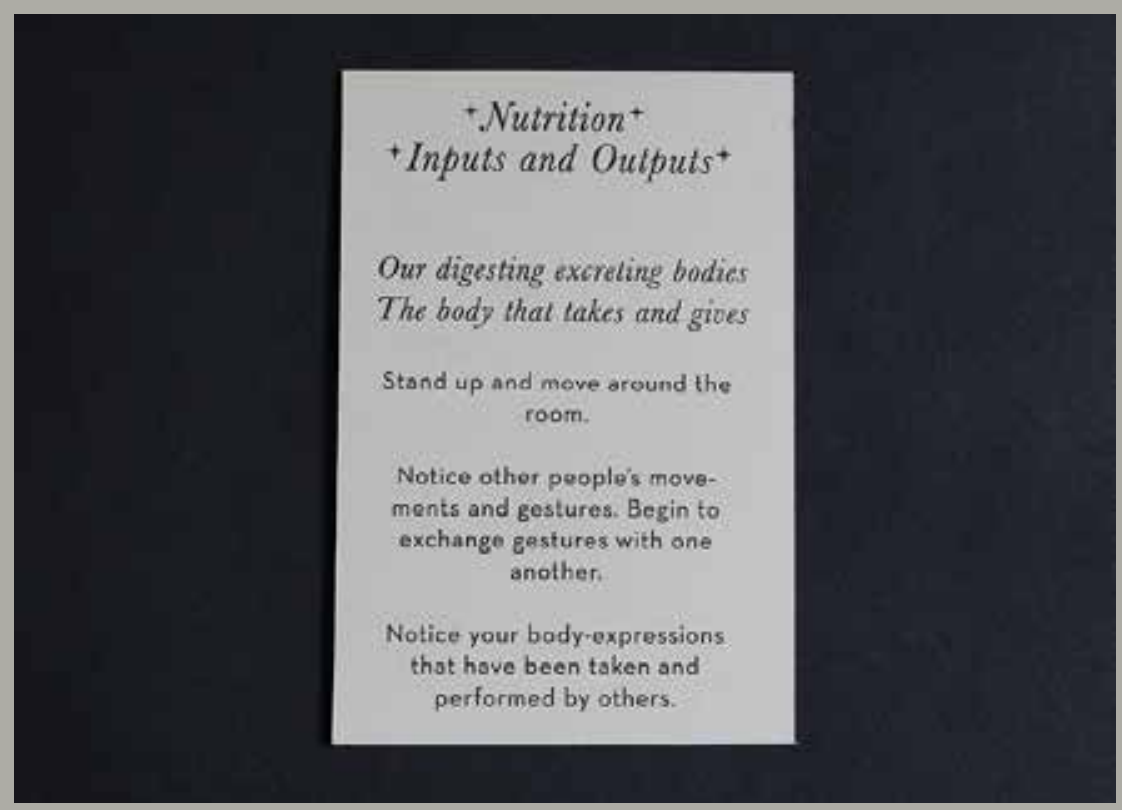

Nutrition|Transformations|Inputs and Outputs card, back 


\section{Nutrition}

Our bodies take - air, food, water, sun, embraces, words... What we let into ourselves has a huge impact on how we feel and who we are. But our bodies also give - fluids, sounds, glances, embraces, words... And what we give and let go also determines us. Sensing and sensitizing to these inputs and outputs grows the awareness of our bodies as actors, mediators, beneficiaries / victims of such circulation.

Nutrition $\mid$ Transformation $\mid$ Inputs and Outputs

Our digesting-excreting body

The body that takes and gives

Stand up and move around the room. Notice other people's movements and gestures. Begin to exchange gestures with one another. Notice your body-expressions that have been taken and performed by others. 


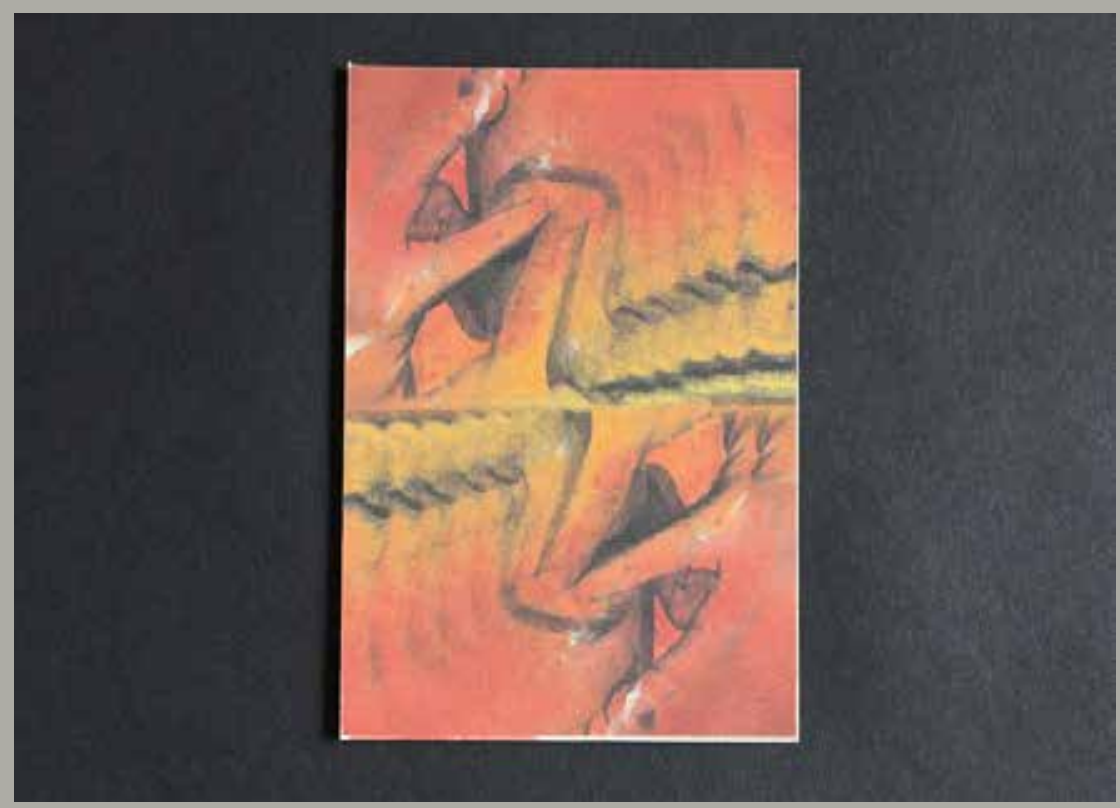

Physical Activity|Sensory Experience card, front

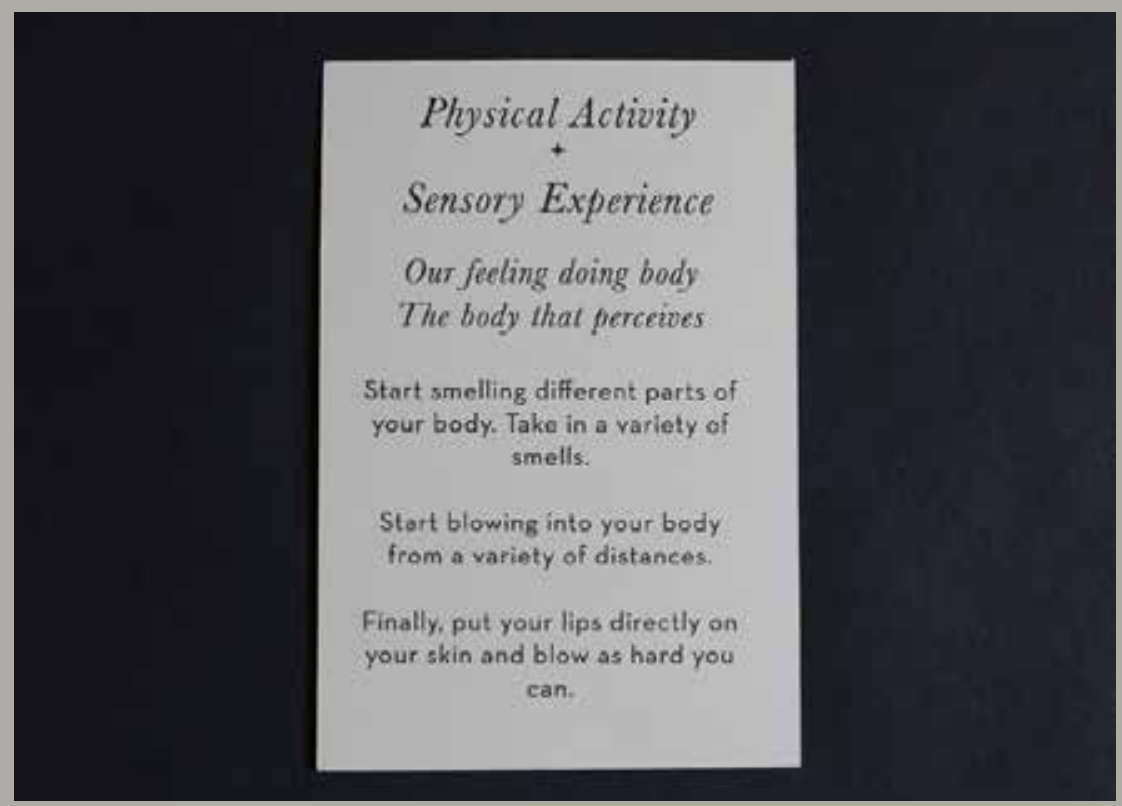

*Physical Activity|Sensory Experience card, back 


\section{Physical Activity and Sensory Experience}

What happens when we grow senses and sensitivities in our bodies? What happens when we feel something on our skin, think it with our minds, and experience it with our emotions? How can this heightened, integrated awareness release blocks to learning and open the student socially, physically, emotionally, and intellectually? Whether our bodies atrophy from exhaustion and/or disuse or whether we live in a state of deep, active body awareness, there is an opening that occurs when we come to see and know the textures, tastes, smells, warmths around us. When we do not simply let these stimuli pass us by, unaware of their impact, we grow agency through awareness. We consider the complex interplays, causal and reactive, between the physical, emotional, intellectual, and social self. We know that when we change the state of one, the other three follow; and when one is degraded or ignored, the others can be dragged along down with it. We can change the body to change the mind, and vice versa, so our task was to create a choreography that changed the state of the body and, along with it, the state of the thinking, feeling, and interacting in order to optimize learning.

\section{Physical Activity | Sensory Experience}

Our feeling-doing body

The body that perceives

Start smelling different parts of your body. Take in a variety of smells. Start blowing into your body from a variety of distances. Finally, put your lips directly on your skin and blow as hard as you can. 


\section{Principles in Practice}

In our process of devising this resource that acknowledges the central role of the body in learning, three principles guided our thinking and making. The first, Ritual/Choreography, addressed our desire to create a "sacred" space at the beginning of any lesson that could be repeatedly used by people to reconnect with their bodies, one another, and the space around them. Creating this special moment, outside the structures of the topic and syllabus, works to catalyze awareness of the multiple points of access to knowledge and experience they offer. The second, Layering/ Adaptability, referred to the body as an entry point to multiple learning experiences (the body as an enabler of connections with ancestry, memory, feelings, sensations, other beings, other worlds...) and to the possibility of using the tool to focus on some or all of these levels as each learning group sees fit. As such, we created this tool so that the deck could keep growing, with new cards added at will. Finally, the principle of Materiality/Visibility emphasizes the importance of the bodies present in a space at the moment of learning. The deck of cards and the wristbands that accompany them were created considering the material and affective aspects of the resource to potentiate embodied experience.

\section{(1) Ritual/Choreography}

"Ritual" and "choreography" are words often associated with automation and routine. But curiously, both of them can also have a radically different reading as facilitators of awareness-creation and intention-setting. $\mathrm{BaM}$ used choreography and ritual in this latter sense. Interaction and continuity, the principles of John Dewey's philosophy of experience, ${ }^{5}$ were prioritized in discussions on what the learning tool ought to contain, how

5 "Education and Experience", 1938 it was to be designed and produced, and why it was necessary to prepare bodies for learning. Ritual and choreography would help us achieve the principles both of interaction and continuity. The deck of cards, inspired by the concept of playing cards and tarot cards, references mystery, exploration, investigation, and play. Each card from this deck contains a score for a choreography. The choreographies thrust the bodies into the present moment, bringing awareness and agency to change over time. These choreographies are meant to be performed at the beginning of an experience, as a ritual that offers an opportunity to stop/separate/mark time by entering into a sequence (first this, then this, then this) and, in doing so, bringing awareness to the body/mindset and offering an opportunity to change it. We understand this ritual as an instance of both hyper-awareness and habit, or hyper-awareness turned into habit. 


\section{(2) Layering/Adaptability}

The specific themes of the working group sessions were wildly different: ancestry and memory, ecosystems, terrestrial existence, and creativity. The approaches used by its members to facilitate each session were equally diverse: from food sharing, body movement, and guided meditation, to artmaking and discussion circles. Learning communities, just as any group of people, are neither homogenous nor the same. Thus, it made no sense to create a one-size-fits-all tool. The deck of cards reflects multiplicity in its modularity, expansion, and appropriation potential. People can use the deck as we have proposed, or in any number of ways they choose.

Since sharing this tool with the School of Apocalypse and the Parsons School of Design community at the beginning of 2017, we realized that there are at least three ways of activating this tool: the cards can be called upon one by one into the learning space (as stated in the introduction card), one card can be chosen at random as if this were a tarot deck, or a specific card could be chosen, depending on the topic/goal of a given lesson. Anyone could make additional cards and add them to the deck. This living deck can always be expanded. People are free to appropriate it and activate it as they see fit.

\section{(3) Materiality/Visibility}

Working on acknowledging and re-embodying the time and place of learning and the experiences of embodied learning had a profound impact on the design of the final product. First, the deck is a physical tool (rather than a digital one), something that people can sense and hold. Second, it is a beautiful artifact, designed to feel precious, special, and carefully crafted. Finally, the wristbands that accompany the cards aim to extend body openness and awareness beyond the performance of the ritual itself: just as the old trick of tying a string around the finger as a reminder of something, the wristbands keep us returning to our bodies for the remainder of the lesson.

In the $\mathrm{BaM}$ working group, bodies were both complex - polyhedral - objects of study and multipurpose tools that enabled us to access different knowledges. But in furthering our understanding of bodies as media, we realized that this "opening" of our bodies to their rich array of possibilities can be facilitated by design. Just as some technologies shut down, ignore, or re-mediate our bodies, others can be used to reclaim, remediate, and potentiate the presence of bodies in space. These radical technologies of presence help us reorient ourselves. To be cons- 


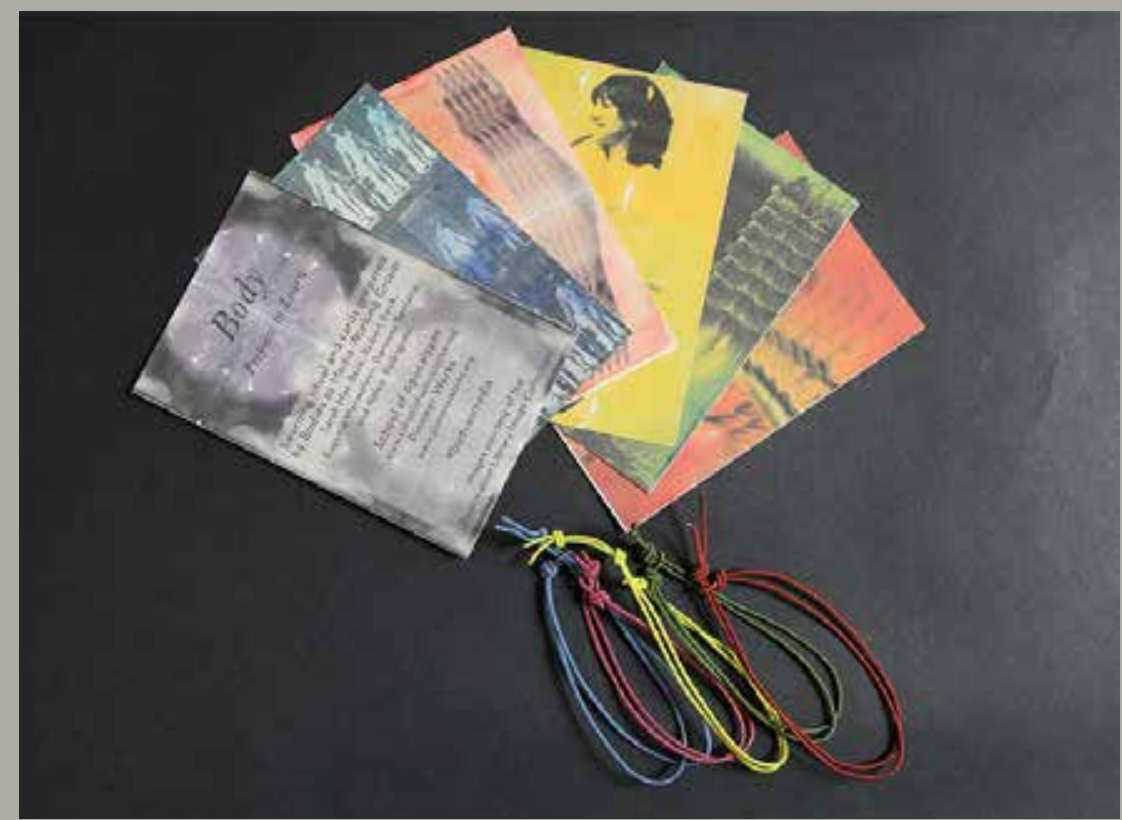

Detail of cards and matching wristbands

tantly reminded that we already posses the ultimate technology - our own bodies - can be deeply liberating and transformatory.

\section{Postscript: What can actually happen when we prepare our bodies to learn}

Upon finishing the tool, Nelesi Rodriguez, one of the BaM working group members, started using the deck of cards in her classroom on a regular basis. Integrated Seminar 2 is a first-year undergraduate course that seeks to provide opportunities for students to explore and better understand how research, thinking, and making are interconnected. This course is a requirement for all undergraduate students at the Parsons School of Design. The class was conformed by a group of 17 students majoring in Fine Arts, Product Design, Strategic Design and Management, Fashion, Illustration, Communication Design, and Architecture. Nelesi added an additional component to the practice of activating the body for learning by beginning each class with a brief conversation highlighting one specific way in which the body enables knowledge and/ or experience. After this very brief introduction, someone in the group (not necessarily the instructor) proceeded to read the corresponding 
${ }^{6}$ The questions guiding students' reflections were: What did you think and how did you feel when we started using the cards? Have your thoughts and feelings evolved as we continued to use them? How? Do you think it has affected your individual experience in this class? How? Do you think it has affected our experience as a group? How? card while the rest participated however they felt appropriate. (Students were invited to enact the score, but they were allowed to just listen to the instructions or leave the room if they wanted to.) Upon finishing the action prompted by the card and depending on the classroom mood each day, Nelesi invited students to comment on their experiences enacting the score and/or simply thanked everyone for becoming present in the classroom.

Predictably, the cards were initially met with skepticism, disorientation, and even some apathy; students quickly started appreciating them as they realized they brought them all in sync and opened spaces for shared release, laughter, reflection, and vulnerability. On their last day as a learning community, Nelesi posed a set of questions and invited students to anonymously share with her their thoughts and feelings about the opening ritual they had enacted week after week. ${ }^{6}$ We present a collection of student responses, which begin to shed light on the ways in which this tool can have an effect (or not) on individual and collective learning.

[At first] I didn't think that it was productive or useful hence I felt weird and uncomfortable doing it. Despite still being a little uncomfortable doing them it made me appreciate it because everyone all participated together [sic].

At first I was confused, but I started realizing why we used them. I started liking some of the exercises. It hasn't really affected my experience in the class, but as a group it has made us more aware of each other and what other people do.

I really liked the cards, it was nice to do them at the beginning of each class because it really woke me up and got me ready to learn. I also really enjoyed and looked forward to doing a new card every class. It really connects us as a class when we participate in these things together.

I thought the idea of using the cards was interesting but not very necessary. In some way it started making me feel more peaceful before starting the class.

At the beginning it was weird and awkward but it then became like a ritual, part of the class. It also acted as a way of connecting to others and laughter too. I think it did affect our group/class since it made it a more approachable, secure place to express our work. 


\section{Reference List}

Crary, J., 2013. 24/7 Late Capitalism and the Ends of Sleep. New York/London: Verso.

Dewey, J., 1938. Experience and Education. First Touchstone Edition.

Dychtwald, K., 1986. Bodymind. New York: Jeremy P. Tarcher/Putnam.

Foucault, M., 1982. Technologies of the Self. In: Foucault, M., Martin, L., Gutman, H. and Hutton, P., eds. 1988. Technologies of the Self: A Seminar with Michel Foucault. Cambridge: University of Massachusetts Press.

Foucault, M., Martin, L., Gutman, H. and Hutton, P., eds. 1988. Technologies of the Self: A Seminar with Michel Foucault. Cambridge: University of Massachusetts Press.

Hooks, B., 1994. Teaching to Transgress: Education as the Practice of Freedom.

New York/London: Routledge.

Wolf, G., 2010. The Data Driven Life. The New York Times, 28 Apr. Available online at: <http:// www.nytimes.com/2010/05/02/magazine/02self-measurement-t.html?_r=0> [Accessed 10 December 2015].

2009. "Know Thyself”. The New York Times, 22 June. Available online at: <http://archive.wired.com/medtech/health/magazine/17-07/lbnp_knowthyself?currentPage=all> [Accessed 9 May 2015]. 


\section{Eugenia Manwelyan}

Choreographer, ecologist, and producer. She is the co-founder of Arts and Ecology, Director of Eco Practicum, a member of the Best Praxis art collective, and a founding faculty of the School of Apocalypse. Her work is rooted in the pedagogies of power, social choreography, and the connections between creative practice and survival. As a visiting faculty at Columbia University, Eugenia has worked on environmental planning and arts projects in the New York bioregion, as well as in India, Vietnam, Jordan, Israel, and Palestine. She holds a BA in International Development from McGill University and her MS in Urban Planning from Columbia University.

\section{Nelesi Rodriguez}

Venezuelan-born media educator, researcher, and practitioner. She's a Fulbright Scholar with a MA in Media Studies from The New School. Her research focuses on contemporary subjectivities and understandings of the body as a medium. Nelesi often employs creative practice as a tool for inquiry. At the same time, her creative and intellectual explorations inform her pedagogy. Currently, she teaches at the Parsons School of Design and conducts research at The New School and the School of Apocalypse. 